\title{
Induced Tetraploidy in a Vaccinium elliottii Facilitates Crossing with Cultivated Highbush Blueberry
}

\author{
I.M. Dweikat and P.M. Lyrene \\ Fruit Crops Department, University of Florida, Gainesville, FL 32611 \\ Additional index words. Vaccinium corymbosum, meiotic irregularities
}

\begin{abstract}
A synthetic autotetraploid derived by colchicine treatment of a Vaccinium elliottii Chapm. plant $(2 n=2 x$ $=24$ ) was used to study the effect of chromosome doubling on the ability of this noncultivated species to cross with the cultivated tetraploid highbush blueberry ( $V$. corymbosum $L$.). Mean pollen germination was $28 \% 1$ for the autotetraploid plant, compared to $53 \%$ for the diploid $V$. elliottii plant. However, the number of seedlings obtained per flower pollinated on the tetraploid highbush cultivar $O$ 'Neal rose from 0.01 when diploid $V$. elliottii was the pollen source to 3.86 when pollen from the autotetraploid $V$. elliottii plant was used. Reciprocal crosses between diploid $V$. elliottii and its autotetraploid and selfs of the autotetraploid produced no seedlings. Meiotic irregularities, such as multivalent during metaphase, laggards, and unequal chromosome disjunction, were observed in the autotetraploid, but most chromosomes were associated as bivalents.
\end{abstract}

Vaccinium section Cyanococcus has been divided into nine diploid $(2 \mathrm{n}=2 \mathrm{x}=24), 12$ tetraploid $(2 \mathrm{n}=4 \mathrm{x}=48)$, and three hexaploid $(2 \mathrm{n}=6 \mathrm{x}=72)$ species (Camp, 1945; Darrow et al., 1944). Genes for important horticultural traits exist at all three ploidy levels; each ploidy level has useful genes not found at the others (Moore, 1965). Cultivated forms exist at the tetraploid and hexaploid levels, but diploid Cyanococcus species are not cultivated.

Vaccinium elliottii is a diploid found from Florida to Virginia and west to Texas. This species generally is low-chilling, early ripening, tolerant of dry upland soils, and disease resistant. Its fruit are very small but otherwise of medium to high quality (Lyrene and Sherman, 1980).

Several large-scale efforts have been made to cross tetraploid $V$. corymbosum cultivars with the diploid wild species $V$. elliottii. These crosses have produced few seedlings, but some vigorous triploid and tetraploid hybrids have been obtained (Lyrene and Sherman, 1983; Munoz and Lyrene, 1985). Two alternative explanations for the low success rate in this interspecific cross are the chromosome number difference and genie differences not related to chromosome number.

Chromosome doubling has been induced in many diploid plant species (Dewey, 1979; Sanford, 1983). The resulting autotetraploids showed changes in fertility, chromosome behavior at meiosis, and plant morphology. In V. atrococcum larger pollen, flowers, and leaves resulted from autotetraploidy, as well as a slight breakdown in self-incompatibility (Draper et al., 1972).

Cytological studies in Vaccinium have revealed generally regular pairing in the diploid species (Longely, 1927), but a few pairing irregularities have been reported in tetraploids (Jelenkovic and Hough, 1970). Our study was carried out to determine the effect of chromosome doubling on overcoming the crossing barriers that exist between $V$. elliottii and the tetraploid highbush V. corymbosum.

\section{Materials and Methods}

The tetraploid V. elliottii clone used in this study, Fla. 519, was derived by in vitro colchicine treatment of two-node cut-

\footnotetext{
Received for publication 22 Jan. 1991. Florida Agricultural Experiment Journal Series no. 9168. The cost of publishing this paper was defrayed in part by the payment of page charges. Under postal regulations, this paper therefore must be hereby marked advertisement solely to indicate this fact.
}

tings from a seedling diploid $(2 \mathrm{n}=2 \mathrm{x}=24)$ V. elliottii (Perry and Lyrene, 1984). The tetraploid highbush ( $V$. corymbosum) 'O'Neal' and 'Sharpblue', a diploid V. elliottii clone, and one clone of $V$. darrowi $(2 n=24)$ were also used in the crosses.

In preparation for crossing, plants that had been growing in the field for $\approx 4$ years were dug in December, potted, chilled at $7 \mathrm{C}$ for 6 weeks, and then transferred to a greenhouse. The autotetraploid V. elliottii clone was self-pollinated and reciprocally crossed to both a cultivated highbush and a diploid $V$. elliottii clone.

Pollen viability was evaluated by in vitro pollen germination of $\approx 2000$ pollen grains on an agar medium supplemented with sugar and nutrients (Goldy and Lyrene, 1983). Pollen stainability was measured on $\approx 1000$ pollen grains using $1 \%$ acetocarmine for $1 \mathrm{~h}$. Scanning electron microscopy was also used to determine the diameter and pollen morphology of $\approx 1000$ pollen grains.

Flower buds from the autotetraploid and the diploid V. elliotti clones were used to study meiosis with a phase-contrast microscope (Dweikat and Lyrene, 1989). Leaf thickness was determined from 50 fully expanded leaves from the autotetraploid and diploid V. elliottii, and leaf area was measured with a LI3000 portable leaf area meter (LI-COR, Lincoln, Neb.). Impressions were made by painting the abaxial surface of five mature leaves from the autotetraploid and diploid V. elliottii with clear fingernail polish. After the impressions had dried, they were stripped off, mounted in drops of water on microscope slides, and used to determine guard cell length under a light microscope.

As the berries ripened in the greenhouse, 20 random berries and 200 seeds were weighed from each clone. The seeds were extracted by hand from ripe berries, and the full-sized seeds were counted. The $F_{1}$ seeds from all greenhouse crosses were air-dried, stored in paper bags at 5C for 6 months, and then sown on peatmoss under intermittent mist in the greenhouse. Germination percentage was determined before seedlings were transplanted to the field.

\section{Results}

Pollen germination on an artificial medium and pollen viability, estimated as percent stainable pollen, were lower in the autotetraploid than in the diploid $V$. elliottii (Table 1). The au- 
Table 1. Average phenotypes for autotetraploid and diploid plants of $V$. elliottii used in the greenhouse crosses.

\begin{tabular}{|c|c|c|c|c|c|}
\hline \multirow[b]{2}{*}{ Characteristic } & \multicolumn{2}{|c|}{ Diploid } & \multicolumn{2}{|c|}{ Autotetraploid } & \multirow[b]{2}{*}{$t$ value } \\
\hline & Range & Mean & Range & Mean & \\
\hline Pollen germination (\%) & $46-60$ & $53.3 \pm 1.51$ & $20-33$ & $27.7 \pm 1.33$ & $12.26^{* *}$ \\
\hline Pollen stainability (\%) & $82-$ & $87.3 \pm 1.34$ & $51-67$ & $59.6 \pm 1.40$ & $14.25^{* *}$ \\
\hline Fruit weight (g) & $0.23-0.44$ & $0.30 \pm 0.01$ & $0.60-0.87$ & $0.66 \pm 0.02$ & $16.4^{* *}$ \\
\hline Seed weight (mg) & $0.57-0.65$ & $0.62 \pm 0.03$ & $0.84-0.90$ & $0.87 \pm 0.06$ & $10.8 * *$ \\
\hline Leaf area $\left(\mathrm{cm}^{2}\right)$ & $1.61-2.78$ & $1.95 \pm 0.13$ & $2.75-5.82$ & $3.89 \pm 0.79$ & $6.85^{* *}$ \\
\hline Leaf thickness $(\mu \mathrm{m})$ & $160-200$ & $182 \pm 0.33$ & $180-230$ & $206 \pm 0.52$ & $3.91^{* *}$ \\
\hline Guard cell length $(\mu \mathrm{m})$ & $12.6-15.7$ & $13.7 \pm 0.30$ & $17.2-21.1$ & $19.2 \pm 0.41$ & $10.79 * *$ \\
\hline Pollen diameter $(\mu \mathrm{m})$ & $28-35$ & $31.4 \pm 1.77$ & $37-47$ & $42.5 \pm 1.96$ & $9.11 * *$ \\
\hline
\end{tabular}

*** Significantat $\mathrm{P}=0.05$ and 0.01 , respectively.

totetraploid had thicker stems, larger flowers (data not shown), and increased fruit and seed weight (Table 1, Fig. 1B). Leaf area of the autotetraploid averaged nearly twice that of the diploid V. elliottii (Table 1, Fig. 1A), but leaves of the former were only slightly thicker than those of the diploid. Stomatal guard cells of the autotetraploid averaged $40 \%$ longer than those of the diploid (Table 1, Fig. 1 C and D). Scanning electron microscopy revealed that pollen from the autotetraploid had a larger diameter than that from the diploid (Table 1, Fig. 1E and F). The pollen walls of both the diploid and autotetraploid

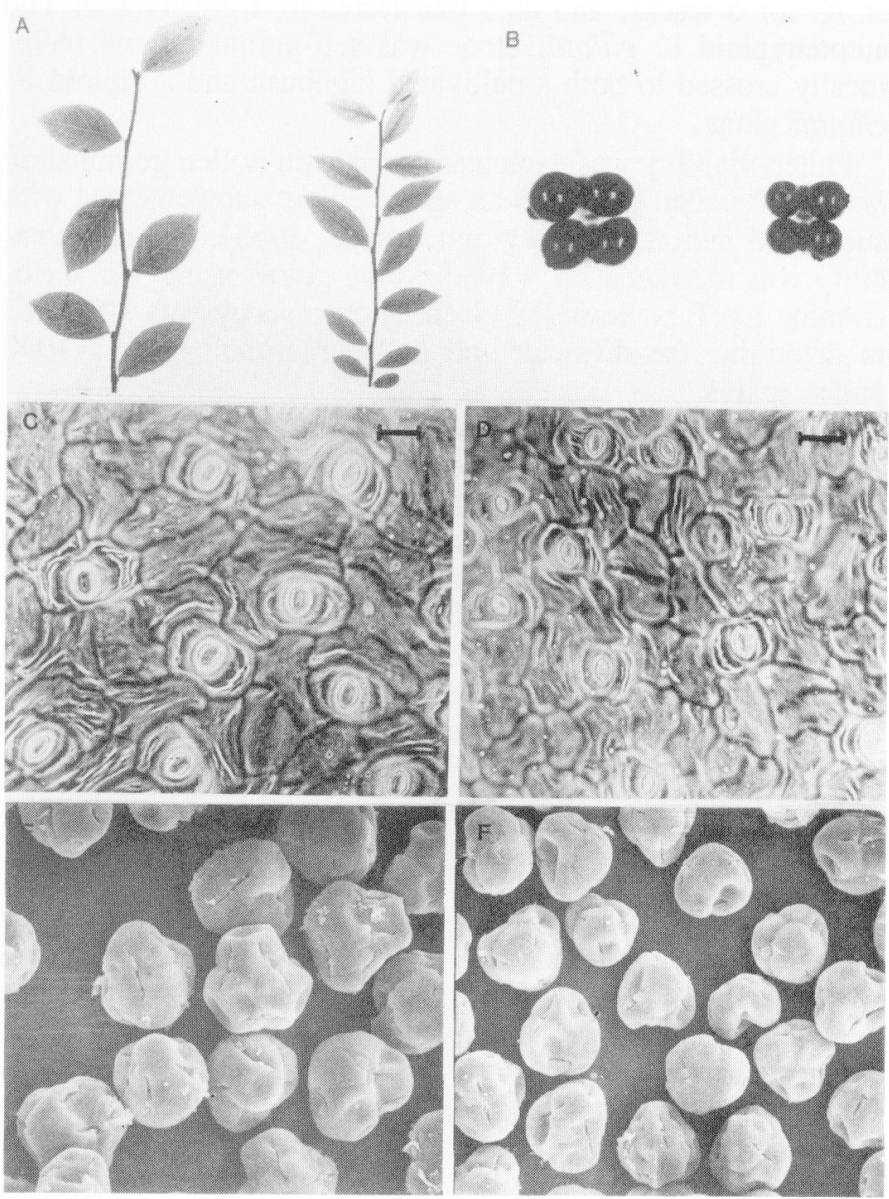

Fig. 1. Mophological characters of diploid and autotetraploid V. elliottii. (A) Branches of autotetraploid (left) and diploid (right).(B) Fruits of autotetraploid (left) and diploid (right). (C) Stomatal guard cells of autotetraploid. (D) Stomatal guard cells of diploid. (E) Autotetraploid pollen. (F) Diploid pollen. Scale $=20 \mu \mathrm{m}$. appeared to be more concave than in previous microphotograph (Maas, 1977). These differences are probably due to technique.

Vaccinium elliottii clone Fla. 519 had medium to high fertility in crosses with the tetraploid V. corymbosum cultivar O'Neal (Table 2). In this cross, Fla. 519 was more fertile as a seed parent than as a pollen parent. When 'O'Neal' was crossed in either direction with the diploid V. elliottii clone, fertility was extremely low. This result is an indication of the strength of the triploid block, which has been observed repeatedly in $4 \mathrm{x} \times 2 \mathrm{x}$ crosses in Vaccinium section Cyanococcus. The tetraploid Fla. 519 set no seed when crossed with diploid V. eliottii was nordirection, suggesting that the triploid block is very strong within $V$. elliottii. Neither the diploid nor the tetraploid $V$. elliottii clone had significant self-fertility (Table 2).

Meiotic chromosomal behavior in diploid V. elliottii was normal in all cells examined (Fig. $2 \mathrm{~A}$ and C). In the autotetraploid, univalent, bivalents, trivalent, and quadrivalents were found (Table 3, Fig. 2 B and D). The mean frequency of chromosome associations other than bivalents was higher at diakinesis than at metaphase I (data not shown). Pairing associations involving more than four chromosomes were absent or rare, but abnormalities, such as clumping of chromosomes at metaphase I, were often observed. At anaphase $\mathrm{I}, \approx 43 \%$ of the cells exam. ined from the autotetraploid had an equal chromosome disjunction (24-24), while the rest of the cells contained one to two laggards (Fig. 2E). By anaphase II, most of the cells examined showed normal chromosome distribution (Fig. 2F).

\section{Discussion}

The reduced pollen viability of the autotetraploid $V$. elliottii clone compared to the diploid $V$. elliottii may be due, in part, to abnormal cytological behavior of the pollen mother cells, as observed in this study, or to genetic and physiological factors (Stebbins, 1947). Since meiosis was normal in the diploid studied, the cytological abnormalities at meiosis in the autotetraploid were regarded as a consequence of chromosome doubling. Univalent, trivalent, and quadrivalents at diakinesis and metaphase I are observed in doubled diploids of may species (Jackson and Casey, 1979). The decrease in trivalent and quadrivalent frequencies from diakinesis to metaphase I was also observed in autotetraploid Fragaria (Sebastiampillai and Jones, 1977).

In most gametophytic incompatibility systems, chromosome doubling has been found to weaken or eliminate the incompatibility (Lewis, 1954; Marks, 1966; Nettancourt, 1969; Pandey, 1956; Sebastiampillai and Jones, 1977). This was not the case in the autotetraploid of $V$. elliottii, supporting earlier reports (El-Agamy, 1979) that the incompatibility in Vaccinium is not gametophytic. 
Table 2. Crossability and fertility data for the autotetraplid V. elliottii clone FL 519.

\begin{tabular}{|c|c|c|c|c|c|c|}
\hline \multicolumn{2}{|c|}{ Cross } & \multirow{2}{*}{$\begin{array}{l}\text { Flowers } \\
\text { pollinated } \\
\text { (no.) }\end{array}$} & \multirow{2}{*}{$\begin{array}{c}\text { Fruit } \\
\text { set } \\
(\%) \\
\end{array}$} & \multirow{2}{*}{$\begin{array}{c}\text { Seeds/fruit } \\
\text { avg } \\
\text { (no.) }\end{array}$} & \multirow{2}{*}{$\begin{array}{c}\text { Seedlings } \\
\text { (no.) }\end{array}$} & \multirow{2}{*}{$\begin{array}{c}\text { Seedlings/ } \\
\text { pollinated } \\
\text { flower } \\
\text { (no.) } \\
\end{array}$} \\
\hline Female & Male & & & & & \\
\hline Fla. $519(4 x)$ & O'Neal $(4 x)^{z}$ & 118 & 62.0 & 15.5 & 850 & 7.21 \\
\hline O'Neal (4x) & Fla. $519(4 x)$ & 185 & 53.0 & 7.7 & 528 & 3.86 \\
\hline O'Neal $(4 \mathrm{x})$ & Sharpblue $(4 x)^{2}$ & 50 & 86.0 & 18.3 & 613 & 12.27 \\
\hline Fla. $519(4 x)$ & $V$ elliottii $(2 \mathrm{x})$ & 1120 & 0.0 & 0.0 & 0 & 0.00 \\
\hline V. elliottii $(2 \mathrm{x})$ & Fla. $519(4 x)$ & 585 & 0.0 & 0.0 & 0 & 0.00 \\
\hline Fla. $519(4 x)$ & Self-pollinated & 892 & 0.0 & 0.0 & 0 & 0.00 \\
\hline V. elliottii $(2 \mathrm{x})$ & Self-pollinated & 650 & 4.3 & 1.7 & 35 & 0.05 \\
\hline$V$. elliottii $(2 \mathrm{x})$ & V. darmowi $(2 \mathrm{x})^{\mathrm{y}}$ & 50 & $89: 0$ & 17.8 & 594 & 11.88 \\
\hline V. elliottii $(2 \mathrm{x})$ & O'Neal $(4 x)$ & 520 & 2.7 & 1.3 & 6 & 0.011 \\
\hline O'Neal (4x) & V. elliottii $(2 \mathrm{x})$ & 479 & 3.1 & 1.3 & 5 & 0.010 \\
\hline
\end{tabular}

${ }^{2}$ Tetraploid $V$. corymbosum cultivar.

A diploid species highly cross-compatible with V. elliottii.

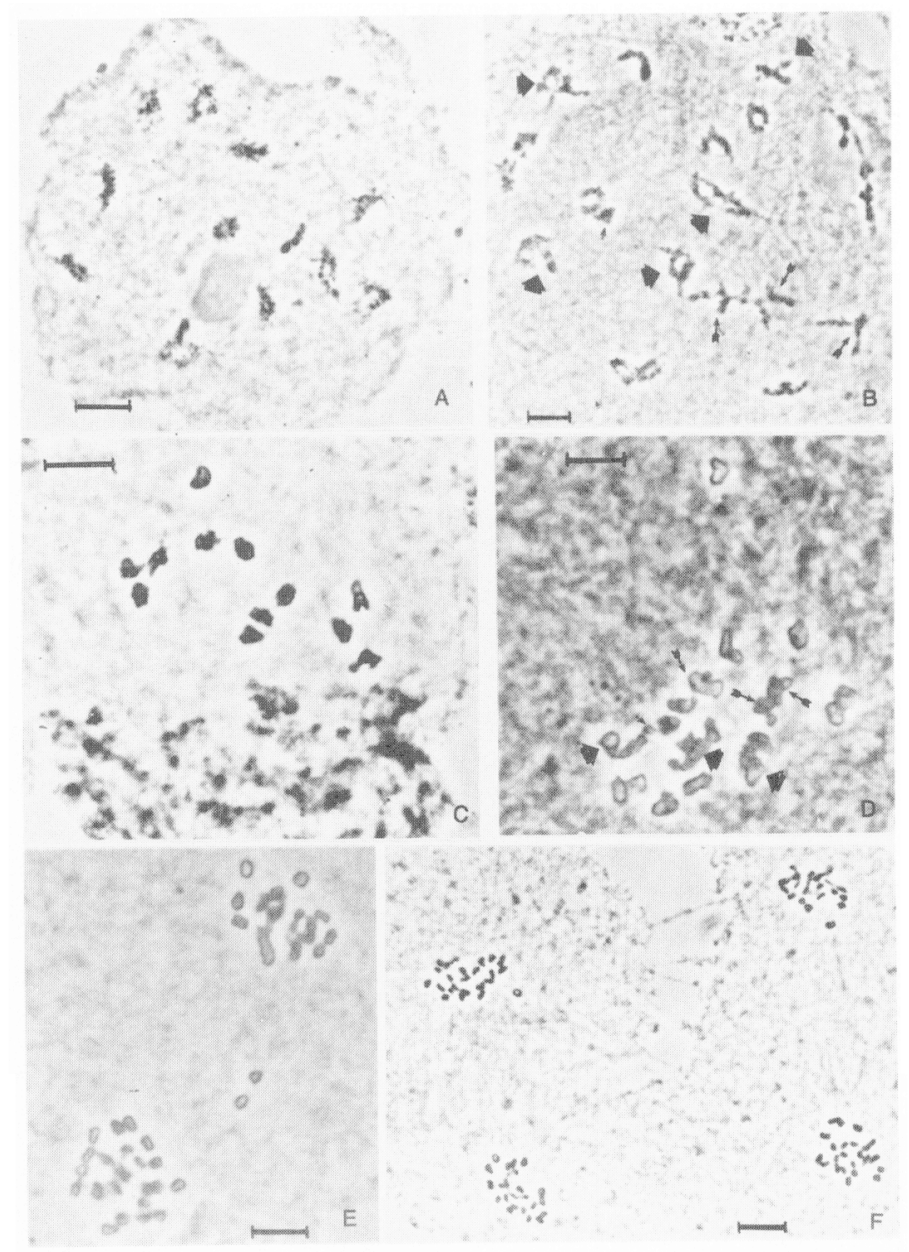

Fig. 2. Chromosome associations at diakinesis and metaphase I in
Table 3. Range and mean of chromosome association at diakinesis (DK) and metaphase I (MI) in the autotetraploid.

\begin{tabular}{cccccc}
\hline \hline \multirow{2}{*}{$\begin{array}{c}\text { Total no. } \\
\text { of cells }\end{array}$} & Stage & \multicolumn{4}{c}{ Range and mean of chromosome association } \\
\cline { 2 - 6 } & I & II & III & IV \\
\hline 27 & DK & $0-3$ & $9-14$ & $0-3$ & $2-5$ \\
& & $(0.96)$ & $(11.62)$ & 2.36 & 4.18 \\
29 & MI & $0-2$ & $10-15$ & $0-3$ & $2-5$ \\
& & $(0.71)$ & $(14.25)$ & $(1.75)$ & $(3.82)$ \\
\hline
\end{tabular}

reported previously (Draper et al., 1972; Moore et al., 1964) and in many other species (Dewey, 1979; Sanford, 1983). The most important morphological feature resulting from chromosome doubling of $V$. elliottii was the increase in fruit size, since small fruit is a major factor preventing cultivation of diploid Vaccinium spp. (Sanford, 1983).

Induced tetraploids in Vaccinium may prove valuable in breeding because they facilitate gene exchange between diploid and tetraploid species. Important traits exist in both diploid and tetraploid species, and direct tetraploid $\times$ diploid crosses give a low frequency of tetraploids, along with triploids, pentaploids, and aneuploids (Lyrene and Sherman, 1983). Doubling the chromosome number of the diploids eliminates or greatly reduces the crossing barrier between diploid and tetraploid Cyanococcus spp. The ease of crossing the species at the tetraploid level suggests a close relationship between $V$. elliottii and $V$. corymbosum and indicates that the crossing barrier between these species is due largely to the difference in ploidy level and not to genie incompatibility.

After obtaining the data reported here, we crossed two unrelated V. elliottii autotetraploids produced by in vitro colchicine treatment and obtained $\approx 100$ seedlings, which then were grown for 3 years in a high-density field nursery. These grew slower than diploid $V$. elliottii seedlings, but survived well in the field, 
readily by their fertile pollen and used in backcrosses to the tetraploid gene pool. The two advantages of this method over induced polyploidy are avoidance of the task of inducing polyploidy and elimination of the 2 to 4 years required for induced polyploids to reach flowering age before they can be used in breeding.

\section{Literature Cited}

Camp, W.H. 1945. The North American blueberries, with notes on other groups of Vacciniaceae. Brittonia 5:203-275.

Darrow,G.M., W.H. Camp, H.E. Fisher, and H. Dermen. 1944. Chromosome numbers in Vaccinium and related groups. Bul. Torrey Bet. Club 71:498-506.

de Nettancourt, D. 1969. Radiation effects on the one-locus-gametophytic system of self-incompatibility in higher plants. Theor. Appl. Genet. 39:187-196.

Dewey, D.R. 1979. Some applications and misapplications of induced polyploidy to plant breeding, p. 445-470. In: W.H. Lewis (cd.). Polyploidy: Biological relevance. Plenum Press, New York.

Draper, A. D., A.W. Stretch, and D.H. Scott. 1972. Two tetraploid sources of resistance for breeding blueberries resistant to Phytophthora cinnamomi Rands. HortScience 7:266-268.

Dweikat, I.M. and P.M. Lyrene. 1989. Production and evaluation of a synthetic hexaploid in blueberry. Theor. Appl. Genet. 77:799804.

El-Agamy, S.Z. 1979. Morphology of pollen incompatibility in blueberries. PhD Diss., Univ. of Florida, Gainesville.

Goldy, R.G. and P.M. Lyrene. 1983. Pollen germination in interspecific Vaccinium hybrids. HortScience 18:54-55.

Jackson, R.C. and J. Casey. 1979. Cytogenetics of polyploids, p. 1754. In: W.H. Lewis (cd.). Polyploidy: Biological relevance. Plenum Press, New York.

Jelenkovic, G. and L.F. Hough. 1970. Chromosome associations in the first meiotic division in three tetraploid clones of Vaccinium corymbosum L. Can. J. Genet. Cytol. 12:316-324.
Lewis, D. 1954. Comparative incompatibility in angiosperms and fungi. Adv. Genet. 6:235-285.

Longley, A.E. 1927. Chromosomes in Vaccinium. Science 66:566567.

Lyrene, P.M. and W.B. Sherman. 1980. Horticultural characteristics of native Vaccinium darrowi, V. elliottii, V. fuscatum, and V. myrsinites in Alachua county, Florida. J. Amer. Soc. Hort. Sci. 105:393396.

Lyrene, P.M. and W.B. Sherman. 1983. Mitotic instability and $2 n$ gamete production in Vaccinium corymbosum $\times$ V. elliottii hybrids. J. Amer. Soc. Hort. Sci. 108:339-342.

Maas, J.L. 1977. Pollen ultrastructure of strawberry and other smallfruit crops. J. Amer. Soc. Hort. Sci. 102:560-571.

Marks, G.E. 1966. The origin and significance of intraspecific polyploidy. Experimental evidence from Solanum chacoense. Evolution 20:552-557.

Moore, J.N. 1965. Improving highbush blueberries by breeding and selection. Euphytica 14:39-48.

Moore, J. N., D.H. Scott, and H. Dermen. 1964. .Development of a decaploid blueberry by colchicine treatment. J. Amer. Soc Hort. Sci. 84:274-279.

Munoz, C.E. and P.M. Lyrene. 1985. Reproductive incompatibility barriers in crosses between Vaccinium corymbosum and V. elliottii. Can. J. Bet. 63:1987-1996.

Pandey, K.K. 1956. Incompatibility in autotetraploid Trifolium pratense. Genetics 41:353-366.

Perry, J.L. and P.M. Lyrene. 1984. In vitro induction of tetraploidy in Vaccinium darrowi, V. elliottii, and V. darrowi $x$ V. elliottii with colchicine treatment. J. Amer. Soc. Hort Sci. 109:4-6.

Sanford, J.C, 1983. Ploidy manipulations, p. 100-123. In: J.N. Moore and J. Janick (eds.). Methods in fruit breeding. Purdue University Press, West Lafayette, Ind.

Sebastiampillai, A.R. and J.K. Jones. 1977. Cytological studies in the genus Fragaria (Rosaceae) 1. Chromosome association and fertility in induced autotetraploids. Cytologia 42:525-534.

Stebbins, G.L. 1947. Types of polyploids. Their classification and significance. Adv. Genet. 1:403-429. 